\title{
Growth response and mycoremediation activity of Coprinus comatus on heavy metal contaminated media
}

\author{
Dulay $\mathrm{RMR}^{1,2 *}$, Pascual $\mathrm{AHL}^{3}$, Constante $\mathrm{RD}^{3}$, Tiniola $\mathrm{RC}^{3}$, Areglo $\mathrm{JL}^{4}$, Arenas \\ $\mathrm{MC}^{4}$, Kalaw $\mathrm{SP}^{1,2}$, and Reyes $\mathrm{RG}^{1,2}$
}

${ }^{I}$ Center for Tropical Mushroom Research and Development, Central Luzon State University, Science City of Munoz, Nueva Ecija, Philippines

${ }^{2}$ Department of Biological Sciences, College of Arts and Sciences, Central Luzon State University, Science City of Munoz, Nueva Ecija, Philippines

${ }^{3}$ Dr. Ramon de Santos School, San Antonio, Cuyapo, Nueva Ecija, Philippines

${ }^{4}$ Nueva Ecija School, Cabanatuan City, Nueva Ecija, Philippines

Dulay RMR, Pascual AHL, Constante RD, Tiniola RC, Areglo JL, Arenas MC, Kalaw SP, Reyes RG 2015 - Growth response and mycoremediation activity of Coprinus comatus on heavy metal contaminated media. Mycosphere 6(1), 1-7, Doi 10.5943/mycosphere/6/1/1

\begin{abstract}
This present work highlighted the effects of heavy metals (lead, copper, chromium and cadmium) on the growth phases of Coprinus comatus and its potential in mycoremediation. The growth response was evaluated on potato sucrose gulaman with varying concentrations $(0 \mathrm{ppm}, 1$ ppm, $10 \mathrm{ppm}$, and $100 \mathrm{ppm}$ ) of the four metals. The ability to accumulate metals was determined on the rice straw - sawdust (7:3 ratio) based substrate formulation infused with $2 \mathrm{ml}$ of $1000 \mathrm{ppm}$ of metals. Metal contents of fruiting bodies were analyzed using atomic absorption spectrophotometer. Results revealed that the growth of mycelia, initiation of primordia and development of fruiting bodies of $C$. comatus were significantly affected by the varying concentrations of the four heavy metals. Apparently, cadmium was the most toxic which significantly recorded the lowest diameter of mycelial growth $(20.75 \pm 0.87 \mathrm{~mm})$, the most extensive periods of primordia (15.00 \pm 0.00 days) and fruiting body $(17.00 \pm 0.00$ days $)$ development at $100 \mathrm{ppm}$ concentration. Among the contaminated substrates, lead produced the highest weight of $3.17 \pm 0.15 \mathrm{~g}$ while cadmium had the lowest weight $(2.10 \pm 0.20 \mathrm{~g})$ of fruiting bodies. Chemical analyses showed that copper was obtained in highest amount (16.78 ppm) while cadmium occurred in lowest amount (10.83 ppm). The high tolerance and the ability to accumulate heavy metals strongly suggest that $C$. comatus is another candidate in mycoremediation.
\end{abstract}

Key words - Coprinus comatus - heavy metals - mycoremediation - mycelia - cadmium.

\section{Introduction}

Heavy metal contamination is one of the most significant environmental concerns in the Philippines. This is prevalent at the mining sites, urban areas, polluted bodies of water, commercial industries and agricultural land areas. Exposure to toxic heavy metals is a severe public health concern due to the harmful effects which may cause illness. The ingestion of contaminated food and water through eating and drinking and inhalation of polluted air results heavy metal poisoning 
(Oghenekaro et al. 2008) or may lead to the development of chronic and cardiovascular diseases (Alissa \& Ferns 2011). In order to address this problem, researchers are introducing technologies that could treat and/or rehabilitate contaminated areas, and one of these is through mycoremediation - sequestration of heavy metals in the environment by fungi particularly mushrooms.

Previously, mushrooms have been utilized as agents of decontamination of various hazardous toxic metals in the soil and sediments because of their high ability to uptake common pollutants such as heavy metals and radionuclides (Urban et al. 2005). A number of mushrooms have been proven to mycoremediate heavy metals which include Pleurotus platypus, Agaricus bisporus, Calocybe indica, Calvatia excipuliformis, Hygrophorus virgineus, Boletus edulis, Lepiotar hacodes, Lepis tanuda, Pleurotus sajor-caju, Pleurotus ostreatus, Psalliota campetris, Russula delica (Elekes \& Busuioc 2010, Vimala \& Das 2009, Nilanjana 2005). Moreover, Pleurotus pulmonarius, Lentinus tigrinus and Polyporus sp. exhibit the ability to degrade persistent aromatic hydrocarbons (Adenipekun et al. 2011, Federici et al. 2011, Hadibarata et al. 2009), P. ostreatus removes polycyclic aromatic hydrocarbon (PAH) in contaminated soil (Eggen \& Majcherzykb 1998), and Bjerkandera sp. degrades dibenzothiophene, fluranthene, pyrene, and chrysene in a soil slurry reactor (Valentin et al. 2007).

Coprinus comatus, locally known as kabuteng itim or kabuteng demonyo, belongs to the family of Agaricaceae has an elongated bullet-shaped with scaly cap and a straight, fibrous and hollow stem at young stage and becomes inky when it matures. This mushroom is usually collected by the farmers on the pile of rice straw in the field every afternoon of the rainy season for food. Reyes et al. (2009) reported that this mushroom contains essential amino acids, namely: valine, leucine, lysine, isoleucine, threonine, phenylalanine, tryptophan, and methionine. Its nutritional composition may vary depending on the substrate used. For instance, basidiocarp grown on $P$. sajor-caju spent with corn grit contained high amount of crude protein $(31.51 \%)$, ash $(8.87 \%)$ and moisture $(14.47 \%)$ while high amount of crude fiber $(8.26 \%)$, carbohydrates $(50.10 \%)$ and lowest fat $(2.05 \%)$ were found in P. ostreatus spent (Dulay et al. 2014). Based on this important information, efforts have been made to domesticate and aseptically cultivate this mushroom as source of functional food. Different production technologies were introduced using rice straw sawdust based substrate (Reyes et al. 2009), reutilizing Pleurotus mushroom spent (Dulay et al. 2014) and using pulp and paper waste from the paper mill (Dulay et al. 2012). However, since some pulp and paper wastes contain lead $(\mathrm{Pb})$, the ability of $C$. comatus to uptake lead from the substrate was also evaluated in the previous study. It was found out that the basidiocarp harvested from the $48 \mathrm{ppm} \mathrm{Pb}$-contaminated paper waste substrate was detected to consist of $16.15 \mathrm{ppm}$ of $\mathrm{Pb}$, indicating its vital role in mycoremediation.

In order to establish benchmark data on the growth response and mycoremediation potential of $C$. comatus on the different heavy metals such as lead, copper, chromium and cadmium, this study was necessarily conducted. The mycelial growth was evaluated on the coconut water media contaminated with varying concentrations of the four heavy metals. The ability of the fruiting body to uptake of heavy metals was assessed using rice straw - sawdust based formulation infused with $1000 \mathrm{ppm}$ of each heavy metal in an aseptic cultivation condition. The growth response and fruiting body production were also determined.

\section{Methods}

\section{Revival of culture and preparation of mycelia discs}

Agar blocks of approximately $10 \mathrm{~mm}^{2} \times 3 \mathrm{~mm}$ from the pure stock culture of C. comatus (from the culture collection of the Center for Tropical Mushroom Research and Development, Science City of Munoz, Nueva Ecija, Philippines) were aseptically transferred into sterilized potato sucrose gulaman (PSG) plates. Culture plates were incubated at room temperature to allow growth of the secondary mycelia. After 7 days of incubation, the mycelial discs were prepared using flame sterile $10 \mathrm{~mm}$ diameter cork borer in the revived culture which served as source of inocula. 


\section{Preparation of potato sucrose gulaman with heavy metals}

Five hundred grams of potato was boiled in $2 \mathrm{~L}$ of distilled water until tender. After boiling, the decoction was obtained and $40 \mathrm{~g}$ of white gulaman and $10 \mathrm{~g}$ of sucrose were added and subsequently boiled, stirred constantly until homogenized. One hundred $\mathrm{ml}$ of the medium was prepared for each concentration. Three concentrations ( $1 \mathrm{ppm}, 10 \mathrm{ppm}$, and $100 \mathrm{ppm})$ of the four heavy metal salts namely; lead sulfate $\mathrm{PbSO}_{4}$, copper sulfate $\mathrm{CuSO}_{4}$, chromium nitrate $\mathrm{Cr}\left(\mathrm{NO}_{3}\right)_{3}$ and cadmium nitrate $\mathrm{CdNO}_{3}$ were evaluated in this study. A heavy metal free medium was also prepared as the control, 0 ppm. Each prepared heavy metal medium was dispensed in a flask, cotton plugged and properly labelled. These were sterilized in an autoclave at $121^{\circ} \mathrm{C}, 15 \mathrm{psi}$ for $30 \mathrm{~min}$.

\section{Evaluation of the secondary mycelia growth of $\boldsymbol{C}$. comatus}

After sterilization, the different media at $40^{\circ} \mathrm{C}$ were pour plated into sterilized Petri plates with three replicates each treatment. Once solidified, the plated media were centrally inoculated with mycelia discs from the revived culture of $C$. comatus. The inoculated plates were incubated at $30{ }^{\circ} \mathrm{C}$ to allow mycelia growth. The daily mycelia growths were measured and the number of days of primordial initiation and fruiting body development were determined.

\section{Mycoremediation and fruiting body performance of $\boldsymbol{C}$. comatus on contaminated media}

The fruiting body production of $C$. comatus in an aseptic condition was followed. Naturally composted rice straw was chopped into 1 inch long and mixed with composted sawdust following the $7: 3 \mathrm{v} / \mathrm{v}$ substrate formulations. Forty grams of the formulated substrate was placed in a miniaturized glass bottle. Each bottled substrate was infused with $2 \mathrm{ml}$ of $1000 \mathrm{ppm}$ of each heavy metal. These were individually covered with polypropylene sheets, secured with a rubber band and sterilized at $15 \mathrm{psi}, 121{ }^{\circ} \mathrm{C}$ for 45 minutes. After cooling, each was inoculated with a $10 \mathrm{~mm}$ diameter mycelia disc of the revived culture of $C$. comatus and subsequently incubated at $30{ }^{\circ} \mathrm{C}$ under alternating light and dark condition. After mycelial colonization, the cultures were placed into a growing chamber with $80-90 \% \mathrm{RH}$ to allow fruiting body development. The premature fruiting bodies were harvested, weighed and air-dried. The heavy metal contents of the mushrooms were analyzed using atomic absorption spectrophotometer.

Data were analyzed using analysis of variance ANOVA in one way classification analysis. LSD was used to determine the significant treatment comparison at 5\% level of significance. The SAS computer program was used for analysis.

\section{Results and Discussion}

\section{Effect of heavy metals on the growth phases of $C$. comatus}

Mushrooms interact with heavy metals physiological and morphologically. Some heavy metals have important biological roles in the fungal metabolism and some are considered toxic at certain concentration (Baldrian 2003). In the present study, the effect of four heavy metals on the different growth phases of $C$. comatus was evaluated. The diameter of mycelial growth after 4 days of incubation and the number of days of primordia and fruiting body development are shown in Table 1. Interestingly, it can be seen that $1 \mathrm{ppm}$ of all the heavy metals significantly stimulated the mycelial growth, which were found higher than the mycelial growth of heavy metal free (control) culture plates. However, lower growth diameters were significantly recorded at $10 \mathrm{ppm}$ and 100 ppm of all heavy metals except in copper, which strongly suggests its less toxicity in C. comatus. Apparently, cadmium was the most toxic among the four heavy metals evaluated since it significantly registered the lowest fungal growth of $38.92 \pm 0.83 \mathrm{~mm}$ and $20.75 \pm 0.87 \mathrm{~mm}$ at 10 ppm and $100 \mathrm{ppm}$ plate cultures, respectively (Figure 1. K and L). This response of $C$. comatus on cadmium is in congruence to the previous findings of Baldrian \& Gabriel (1997) who reported that cadmium and mercury showed the highest toxicity in Stereum hirsutum. 
Table 1 Mycelial growth diameter after 4 days of incubation and number of days of development of primordia and fruiting bodies grown on the different concentrations of heavy metals

\begin{tabular}{|c|c|c|c|c|}
\hline \multirow[t]{2}{*}{ Heavy metals } & \multirow{2}{*}{$\begin{array}{c}\text { Concentration } \\
(\mathbf{p p m})\end{array}$} & \multirow{2}{*}{$\begin{array}{c}\text { Mycelial growth } \\
\text { (mm) }\end{array}$} & \multicolumn{2}{|c|}{ Number of days of development of } \\
\hline & & & Primordia & Fruiting body \\
\hline \multirow{4}{*}{ Lead } & 0 & $50.67 \pm 0.58^{\mathrm{b}}$ & $4.00 \pm 0.00^{\mathrm{b}}$ & $5.00 \pm 0.00^{\mathrm{b}}$ \\
\hline & 1 & $56.42 \pm 1.04^{\mathrm{a}}$ & $4.33 \pm 0.58^{\mathrm{b}}$ & $5.33 \pm 0.58^{\mathrm{b}}$ \\
\hline & 10 & $48.25 \pm 0.43^{\mathrm{c}}$ & $4.67 \pm 0.58^{\mathrm{b}}$ & $5.67 \pm 0.58^{\mathrm{b}}$ \\
\hline & 100 & $49.08 \pm 0.29^{\mathrm{c}}$ & $5.67 \pm 0.58^{\mathrm{a}}$ & $7.67 \pm 0.58^{\mathrm{a}}$ \\
\hline \multirow{4}{*}{ Copper } & 0 & $50.67 \pm 0.58^{\mathrm{c}}$ & $4.00 \pm 0.00^{\mathrm{b}}$ & $5.00 \pm 0.00^{\mathrm{b}}$ \\
\hline & 1 & $57.00 \pm 0.43^{\mathrm{a}}$ & $5.00 \pm 0.00^{\mathrm{a}}$ & $6.33 \pm 0.58^{\mathrm{a}}$ \\
\hline & 10 & $53.33 \pm 0.52^{\mathrm{b}}$ & $5.00 \pm 0.00^{\mathrm{a}}$ & $6.33 \pm 0.58^{\mathrm{a}}$ \\
\hline & 100 & $53.52 \pm 0.25^{\mathrm{b}}$ & $5.00 \pm 0.00^{\mathrm{a}}$ & $6.33 \pm 0.58^{\mathrm{a}}$ \\
\hline \multirow{4}{*}{ Chromium } & 0 & $50.67 \pm 0.58^{\mathrm{b}}$ & $4.00 \pm 0.00^{\mathrm{c}}$ & $5.00 \pm 0.00^{\mathrm{b}}$ \\
\hline & 1 & $56.57 \pm 0.64^{\mathrm{a}}$ & $4.33 \pm 0.58^{\mathrm{c}}$ & $5.67 \pm 0.58^{\mathrm{b}}$ \\
\hline & 10 & $51.07 \pm 1.12^{\mathrm{b}}$ & $5.33 \pm 0.58^{\mathrm{b}}$ & $6.00 \pm 1.00^{\mathrm{b}}$ \\
\hline & 100 & $48.03 \pm 0.70^{\mathrm{c}}$ & $6.33 \pm 0.58^{\mathrm{a}}$ & $7.67 \pm 0.58^{\mathrm{a}}$ \\
\hline \multirow{4}{*}{ Cadmium } & 0 & $50.67 \pm 0.58^{\mathrm{b}}$ & $4.00 \pm 0.00^{\mathrm{b}}$ & $5.00 \pm 0.00^{\mathrm{b}}$ \\
\hline & 1 & $55.83 \pm 0.88^{\mathrm{a}}$ & $4.33 \pm 0.58^{\mathrm{b}}$ & $5.00 \pm 0.00^{\mathrm{b}}$ \\
\hline & 10 & $38.92 \pm 0.83^{\mathrm{c}}$ & $4.33 \pm 0.58^{\mathrm{b}}$ & $5.33 \pm 0.58^{\mathrm{b}}$ \\
\hline & 100 & $20.75 \pm 0.87^{\mathrm{d}}$ & $15.00 \pm 0.00^{\mathrm{a}}$ & $17.00 \pm 0.00^{\mathrm{a}}$ \\
\hline
\end{tabular}

(In Table: Treatment means in each heavy metal with the same letter of superscript are not significantly different from each other at $5 \%$ level of significance using LSD.)

Similarly, the initiation of primordia and development of fruiting bodies of C. comatus were significantly affected by the varying concentrations of the four heavy metals. The $100 \mathrm{ppm}$ of lead, chromium and cadmium (Figure 1. C, I, and L) significantly delayed the emergence of the primordia and fruiting bodies while those at $10 \mathrm{ppm}$ or lower concentrations were statistically comparable to the control plates. On the other hand, although $1 \mathrm{ppm}$ or higher concentrations of copper showed significant difference with the control plates, the periods for primordia and fruiting body development were not those extremely extensive when compared to the $100 \mathrm{ppm}$ of the other heavy metals. Cadmium at $100 \mathrm{ppm}$ apparently recorded the most extensive periods of primordia and fruiting body development of $C$. comatus. This delayed growth and development of fruiting bodies could be explained by the disturb metabolic processes at the cellular level of the fungus caused by the toxic metals which could possibly lead to the different morphological changes that are necessary to investigate in the future study. Previously, some morphological changes on the stipe length, stipe diameter, and cap diameter of $P$. tuberregium grown on lead and cadmium fortified soil were obviously observed in the study conducted by Akpaja et al. (2012). Although growth and development of $C$. comatus were obviously affected by the different heavy metals, its high metal tolerance is noteworthy to consider as its important role in mycoremediation.

\section{Performance of fruiting body and mycoremediation activity of $C$. comatus}

With the established high tolerance on the varying concentrations of the four heavy metals, the mycoremediation activity of $C$. comatus was also considered in the present work. Table 2 presents the weight and heavy metal contents of fruiting bodies of $C$. comatus grown on the heavy metal contaminated substrates. Contaminated substrates significantly produced lower weight of 


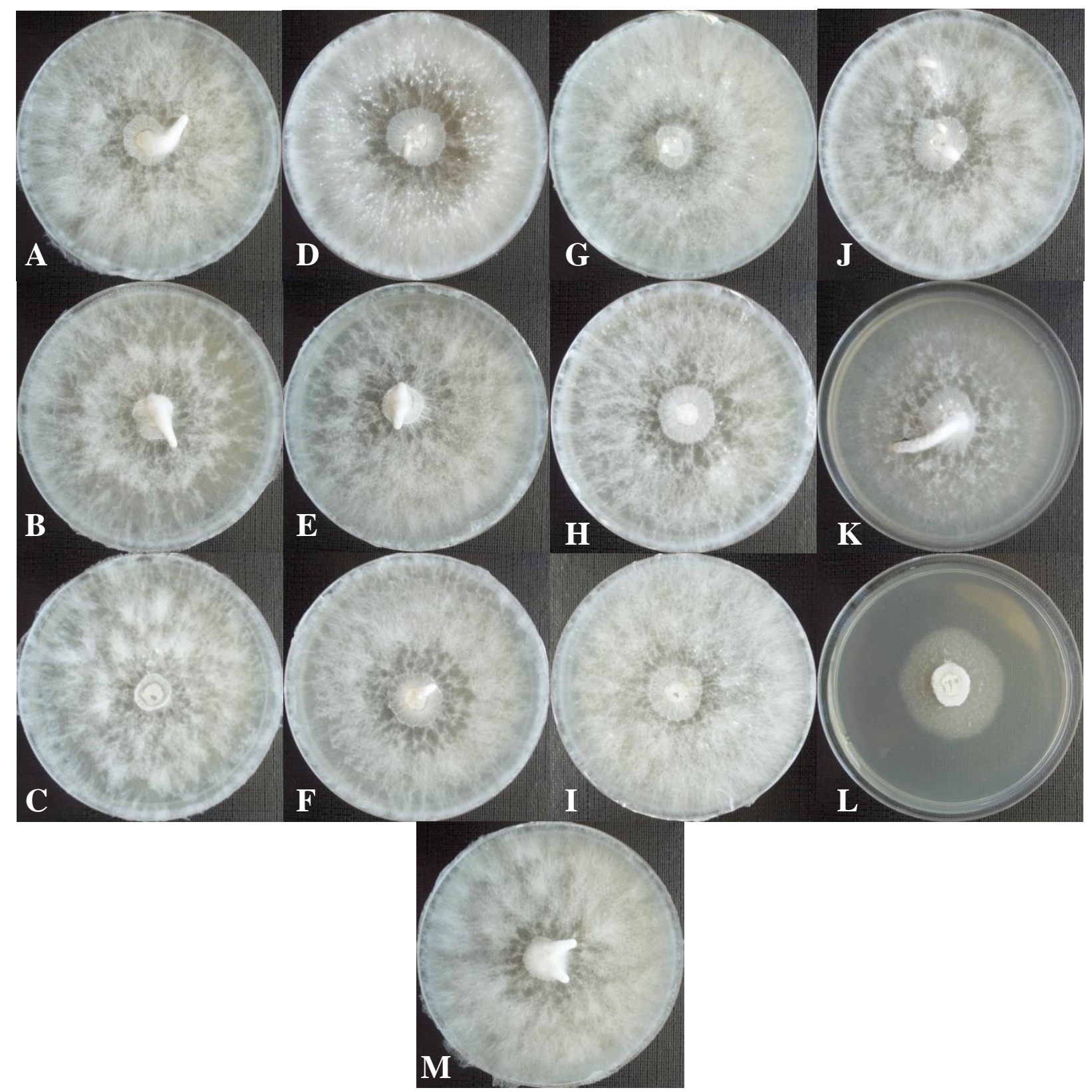

Fig. 1 - Culture plates of C. comatus on the media with the different concentrations (1 ppm, 10 $\mathrm{ppm}$, and $100 \mathrm{ppm}$, from top to bottom) of heavy metals, namely: lead (ABC); copper (DEF); chromium (GHI); and cadmium (JKL) and 0 ppm, heavy metal free (M) after 5 days of incubation.

fruiting bodies compared to the weight produced in the control. Among the contaminated substrates, lead produced the highest weight of $3.17 \pm 0.15 \mathrm{~g}$ which statistically comparable with chromium. In contrast, substrate with cadmium had the lowest weight $(2.10 \pm 0.20 \mathrm{~g})$ of fruiting bodies. Apart from the growth and development, the production performance of $C$. comatus was also significantly influenced by the four heavy metals.

Fungi particularly mushrooms have powerful degrading capabilities. They have extracellular degrading system which enables them to degrade compounds that are not easily taken up by their cells such as lignin and many hazardous environmental pollutants like heavy metals (Barr \& Aust 1994, Martens \& Zadrazil 1998). The amount of heavy metals (Table 2) present in the fruiting bodies showed in this study reflecting the mycoremediation capability of C.comatus. The ability of the fruiting bodies to uptake varied depending on the metal types. Copper was obtained in highest amount while cadmium occurred in lowest amount. These results are in conformity with the previous observations of Dogan et al. (2006) who reported that heavy metal concentrations vary 
Table 2 Weight and heavy metal contents of fruiting bodies of $C$. comatus grown on the heavy metal contaminated substrates.

\begin{tabular}{lcc}
\hline Heavy metals & $\begin{array}{c}\text { Weight of fruiting bodies } \\
(\mathbf{g})\end{array}$ & $\begin{array}{c}\text { Amount of heavy metal } \\
\text { in fruiting bodies (ppm) }\end{array}$ \\
\hline Lead & $3.17 \pm 0.15^{\mathrm{b}}$ & 15.13 \\
Copper & $2.23 \pm 0.31^{\mathrm{c}}$ & 16.78 \\
Chromium & $2.87 \pm 0.35^{\mathrm{b}}$ & 15.17 \\
Cadmium & $2.10 \pm 0.20^{\mathrm{c}}$ & 10.83 \\
Control (-) & $4.07 \pm 0.15^{\mathrm{a}}$ & ND \\
\hline
\end{tabular}

(In Table: Treatment means with the same letter of superscript are not significantly different from each other at 5\% level of significance using LSD. ND; not detected.)

depending on metal types and mushroom species types. For instance, the highest metal concentrations of $39 \mathrm{mg} / \mathrm{kg}$ lead and $3.72 \mathrm{mg} / \mathrm{kg}$ cadmium were determined in Trichaptum abietinum, $326 \mathrm{mg} / \mathrm{kg}$ copper in Trametes versicolor, $467 \mathrm{mg} / \mathrm{kg}$ manganese in Panaeolus sphinctrinus, $69.4 \mathrm{mg} / \mathrm{kg}$ nickel in Helvella spadicea, $84.5 \mathrm{mg} / \mathrm{kg}$ chromium in Phellinus igniarius, and $6.97 \mathrm{mg} / \mathrm{kg}$ silver in Agaricus campestris while the minimum amounts were in Amanita vaginata (2.22 mg/kg cadmium), Pleurotus eryngii $(1.52 \mathrm{mg} / \mathrm{kg}$ lead), and Helvella leucomelana (60.2 $\mathrm{mg} / \mathrm{kg}$ copper). Moreover, the level of copper ranged from $0.45 \mathrm{mg} / 100 \mathrm{~g}$ in $P$. atroumbonata and $0.56 \mathrm{mg} / 100 \mathrm{~g}$ in L. squarrosulus. Iron ranged from $0.44 \mathrm{mg} / 100 \mathrm{~g}$ in L. squarrosulus to 1.37 $\mathrm{mg} / 100 \mathrm{~g}$ in $P$. atroumbonata. Manganese ranged from $2.89 \mathrm{mg} / 100 \mathrm{~g}$ to $3.75 \mathrm{mg} / 100 \mathrm{~g}$ in $L$. squarrosulus, while nickel ranged from $0.14 \mathrm{mg} / 100 \mathrm{~g}$ to $0.48 \mathrm{mg} / 100 \mathrm{~g}$ in L. squarrosulus and $P$. tuberregium, respectively. In contrast, cadmium and lead were not detected in Lentinus squarrosulus, Pleurotus tuberregium, and Psathyrella atroumbonata but chromium was in low concentration in L. squarrosulus (Ayodele \& Odogbili 2010).

In the present work, the varying quantities of metals taken up by the fruiting bodies could be due to the role that metal plays in fungal metabolism. In every living organism, small quantities of certain metals (e.g. iron, copper, zinc, and manganese) are nutritionally essential, but in high amounts of any heavy metals may cause toxic effects. In human, these include damaged to vital organs and reduced mental and central nervous function. Thus, collection of mushrooms for food from the wild particularly in areas with heavy metal contamination is unsafe and highly not recommended for human consumption.

Looking at the positive side, this ability of $C$. comatus to accumulate metals strongly dictates its ecological importance and environmental impact. This basidiomycete can be used as mycoremediation agent to treat or rehabilitate areas prevalently contaminated with heavy metals. However, understanding the mechanisms of accumulation is highly considered in the future studies.

\section{Acknowledgement}

The authors wish to thank the staffs of the Center for Tropical Mushroom Research and Development for their untiring assistance during the conduct of this study.

\section{References}

Adenipekun CO, Ayanleye OO, Oyetunji OJ. 2011 - Bioremediation of soil contaminated by spent diesel oil using Pleurotus pulmonarius Fries (Quelet) and its effects on the growth of Corchorus olitorius. Journal of Applied Biosciences 68, 5366-5373.

Akpaja EO, Nwogu NA, Odibo EA. 2012 - Effect of some heavy metals on the growth and development of Pleurotus tuberregium. Mycosphere 3(1), 57-60.

Alissa EM, Fern GA. 2011 - Heavy Metal Poisoning and Cardiovascular Disease. Journal of Toxicology 01/2011; 2011: 870125. DOI: 10.1155/2011/870125. Source: PubMed. 
Ayodele SM, Odogbili OD. 2010 - Metal impurities in three edible mushrooms collected in Abraka, Delta State, Nigeria. Micologia Aplicada International 22(1), 27-30.

Baldrian P, Gabriel J. 1997 - Effect of heavy metals on the growth of selected wood-rotting basidiomycetes. Folia Microbiologica 42, 521-523.

Baldrian P. 2003 - Interactions of heavy metals with white-rot fungi. Enzyme Microbiology and Technology 32, 78-91.

Barr DP, Aust SD. 1994 - Mechanisms white rot fungi use to degrade pollutants. Environmental Science \& Technology 28, 78-87.

Doĝan HH, Sanda MA, Uyanöz R, Öztürk C, Cetin U. 2006 - Contents of metals in some wild mushrooms. Biological Trace Element Research 110(1), 79-94.

Dulay RMR, Gagarin WS, Abella EA, Kalaw SP, Reyes RG. 2014 - Aseptic cultivation and nutrient compositions of Coprinus comatus (O.F. Müll.) Pers. on Pleurotus mushroom spent. Journal of Microbiology and Biotechnology 4(3), 1-7.

Dulay RMR, Parungao AG IV, Kalaw SP, Reyes RG. 2012 - Aseptic cultivation of Coprinus comatus (O. F. Mull.) Gray on various pulp and paper wastes. Mycosphere 3(3), 392-397.

Eggen T, Majcherzykb A. 1998 - Removal of polycyclic aromatic hydrocarbon (PAH) in contaminated soil by white rot fungi, Pleurotus ostreatus. International Biodeterioration \& Biodegradation 41, 111-117.

Elekes CC, Busuioc. 2010 - The biomineral concentrations and accumulation in some wild growing edible species of mushrooms. Annals Food Science and Technology 11(1), 74-78.

Federici E, Giubilei MA, Cajthaml T, Petruccioli M, D’Annibale A. 2011 - Lentinus (Panus) tigrinus augmentation of a historically contaminated soil: matrix decontamination and structure and function of the resident bacterial community. Journal of Hazardous Materials 186 (2-3), 1263-1270.

Hadibarata T, Tachibana S, Itoh K. 2009 - Biodegradation of chrysene, an aromatic hydrocarbon by Polyporus sp. S133 in liquid medium. Journal of Hazardous Materials 164, 911-917.

Martens R, Zadrazil F. 1998 - Screening of white rot fungi for their ability to mineralize polycyclic aromatic hydrocarbons in soil. Folia Microbiologica 43, 97-103.

Nilanjana D. 2005 - Heavy metals biosorption by mushrooms. Nat Prod Rad 4(6), 454-459.

Oghenekaro AO, Okhuoya JA, Akpaja EO. 2008 - Growth of Pleurotus tuberregium (Fr) Singer on some heavy metal-supplemented substrates. African Journal of Microbiology Research 2, 261-271.

Reyes R, Lopez LLM, Kalaw S, Kumakura K, Kikukawa T, Eguchi F. 2009 - Coprinus comatus, a newly domesticated wild nutriceutical mushroom in the Philippines. Journal of Agricultural Technology 5(2), 299-316.

Urban PL, Bazala MA, Asztemborska M, Manjon JL, Kowalska J, Pianka D, Steborowski D, Kuthan RT. 2005 - Preliminary study of platinum accumulation in the fruitbodies of a model fungal species. Nukleonika (Supplement 1), 63-67.

Valentin L, Lu-Chau TA, Lopez C, Feijoo G, Moreira MT, Lema JM. 2007 - Biodegradation of dibenzothiophene, fluranthene, pyrene, and chrysene in a soil slurry reactor by the white-rot fungus Bjerkandera sp. BOS55. Process Biochemistry 42, 641-648.

Vimala R, Das N. 2009 - Biosorption of cadmium (II) and lead (II) from aqueous solutions using mushrooms: a comparative study. Journal of Hazardous Materials 168(1), 378-382. 